\section{RGO move FAR from OK}

SIR-Your correspondents in the somewhat unfortunately titled letter "RGO move OK" (Nature 322, 402; 1986), claim that Nature does not fully realize the implications of the move of the Royal Greenwich Observatory (RGO) to Cambridge. This shortcoming is clearly not unique.

They state that the move to Cambridge will consolidate research astronomy with instrument science and engineering. Yet this ignores both the stated policy of SERC and its recent history in directing the affairs of RGO.

When many people now working in high technology at RGO were recruited, they joined a national observatory in its own right. The research programme was then considered an important part of the life of the observatory, while traditional long-term projects were considered of value and were pursued vigorously. Although instrumentation at that stage had not kept up with the other work, a very positive environment allowed and encouraged the introduction of the advanced instrumentation and engineering techniques essential to an international clsss observatory.

Over the past few years, however, SERC has sought to erode this by a process of attrition: it has restricted the astronomical research role to ten per cent of manpower effort; it has continually cast doubt on the long-term projects being carried out here; and now, in its current forward look, it has established firm plans to cut severely the applied science and engineering aspects of the work. The result will be that manpower allocated to this area in 1990 will be around one-third of its 1982 level, of which a significant fraction will be allocated to La Palma for maintenance support. Clearly the capability of RGO in 1990 , particularly in instrumentation and technology, will be nothing like as great as it is today.

It has been stated by SERC that the move must be self-financing. This can be achieved only by selling the Herstmonceux site, which is immeasurably more valuable to SERC than its sale price can possibly be. Even then, the move cannot be made self-financing without cutting manpower dramatically or greatly reducing the facilities available. It appears that SERC plans to follow both courses of action and will impose a burden on the university to make up for the shortfall in support.

This curious view of economics by SERC is not confined to RGO. The recent withdrawal from the South African Astronomical Observatory and nearwithdrawal from the Anglo-Australian Observatory (AAO) have similar implications. Had the AAO withdrawal occurred (and the agreement must still be consi- dered under threat), SERC would have spent about $£ 30$ million on La Palma without any significant corresponding increase in the observing time available to $\mathrm{UK}$ astronomers. The generosity of SERC in providing capital facilities, which you so rightly mention in your leading article of 3 July $(322,1 ; 1986)$, could surely have been put to better effect when considering the resources necessary to run those facilities that already exist.

What makes the prospect of a move to Cambridge so dismal is not just the upheaval and waste of effort involved, but the fact that there will be no change in style of management by SERC. There will be the same unwillingness to state aims and to provide the resources to execute those aims (or to reduce them correspondingly); there will be the same cavalier attitude to staff morale; there will be the same excessive concentration on capital facilities at the expense of running existing facilities to produce science.

It therefore seems likely that what the University of Cambridge expects and what it receives will not correspond.

We strongly urge the chairman and council of SERC to reconsider their decision in order to minimize the serious damage already done. Perhaps we could then sit down together, in the democratic manner that you mention in your leading article, and discuss long-term aims that would offer British astronomy the best prospects for the future; council's plans clearly do not do that at present.

I.G. VAN BREDA \& P.D. READ Royal Greenwich Observatory,

Herstmonceux Castle.

Hailsham, East Sussex BN27 1RP, UK

SIR-Contrary to your headline-writer's caption to the letter (Nature 322, 402; 1986) about the proposed move of the Royal Greenwich Observatory (RGO) to Cambridge, the RGO move is NOT OK. The move to Cambridge is merely the least of several evils - but the Science and Engineering Research Council (SERC) may also have miscalculated the cost.

The rumour mill suggests that the cost of moving RGO is roughly $£ 6$ million and SERC claims that the move can be selffinancing. However, cursory research will uncover various press articles on the current slump in the price of castles (see, for example, an article in the Sunday Times of 13 July). Apparently "Fort Belan, an 18th century fort complete with cannon, drawbridge and ramparts guarding the Menai Straights in North Wales has still not found any takers (although it has been offered) complete with an airfield, three miles of coastline and a dockyard for $£ 750,000$."
Agricultural land, the property associated with Herstmonceux Castle, is at its lowest value for years, partly due to changes to the agricultural support policies of the European Communities and partly amplified by the dumping of land by city speculators. I conclude that it is highly improbable that the sale of the castle will fetch much more than $£ 0.5$ million. I fear that SERC will be committed to the move before its illusions about the value of the Herstmonceux site are shattered. Having to find $£ 5$ million will pauperize UK astronomy and further reduce SERC's funding of other sciences.

Either SERC must experimentally establish the value of Herstmonceux Castle by putting it on the market before it takes irrevocable steps or the Treasury must reject this "self-financing" proposal as based on an untested theory. Factor-often errors may be acceptable in astronomy but not in the financial provision for it.

Rose Lodge, Michael Penston

Magham Down,

Hailsham BN27 1PR, UK

\section{Fish-eating Eskimos?}

SIR-Your Washington correspondent Tim Beardsley's account of the US nutritional research scene ${ }^{1}$ refers to the "low rate of heart disease among Eskimos who eat a lot of fish". But of the sixteen major Eskimo groupings in the western Arctic zone $^{2}$, only three (Aleut Eskimos, Southern Alaskan and Western Alaskan Eskimos) ingest fish as a portion of their daily diet. Most consume lipids of marine mammalian origin.

The beneficial effects of omega- 3 polyunsaturated fatty acids derived from marine sources were reported by Dyerberg's group ${ }^{3-5}$ based on their studies on Greenland Eskimos who predominantly consume whales and seals, but not fish. Bang et $a .^{3}$ reported that the frequency score of meals (average number during one week's consumption) eaten by Greenland Eskimos decreased in the following order; seal meat and blubber 6.4 ; whale meat and blubber 5.7; soup with seal meat 2.3; fish 1.4; and seal intestines 0.6 . It is also interesting to note that the word Eskimo is apparently derived from a Cree Indian word, meaning "eaters of raw meat".

\section{Laboratory of Marine Biochemistry,}

Faculty of Agriculture,

University of Tokyo,

Bunkyo-ku, Tokyo 113,

Japan

1. Beardsley, T. Nature 322, 104 (1986).

. Carter, W.K.C. Encyclopedia Britannica Vol. 1, 15th edn 1126 (Encyclopedia Britannica Inc., Chicago, 1983)

3. Bang, H.O., Dyerberg, J. \& Hjørne, N. Acta med. Scand. 200, 69-73 (1976)

4. Bang, H.O., Dyerberg, J. \& Sinclair, H.M. Amer. J. Clin. Nutr. 33, 2657-2661 (1980)

Dyerberg, J. Nutr. Rev. 44, 125-134 (1986) 